\title{
Consumo de Álcool em uma comunidade Venezuelana: Pesquisa etNográficA*
}

\section{Maria Cristina Silva Costa ${ }^{1}$; Carlos Onorio Castillo ${ }^{2}$}

Esta é uma pesquisa etnográfica baseada na antropologia interpretativa, que objetiva identificar e interpretar significados do consumo de álcool em comunidade venezuelana. Participaram membros adultos de seis famílias da comunidade. Observação participante e entrevistas foram as técnicas utilizadas. Os sentidos identificados na análise dos dados convergem para três unidades de significação: consumo excessivo, embriaguez e alegria. Para os participantes, a associação de bebidas alcoólicas, alegria, diversão e festa motiva para beber; o beber normal e o patológico se dispõem em um contínuo; a felicidade é subordinada ao consumo de álcool. A pesquisa oferece bases para a assistência à saúde da comunidade. Descritores: Alcoolismo; Antropologia Cultural; Família; Saúde Pública.

\section{Alcohol USE in a VenEzUElan COMMUNity: An ETHNOGRAPHic RESEARCH ${ }^{\dagger}$}

This ethnographic study was performed based on interpretative anthropology, with the purpose to identify and interpret meanings of alcohol use in a Venezuelan community. Participants were adults of six families from the community. The techniques used were participant observation and interviews. The meanings identified in the data analysis converge to three meaning units: excessive use, drunkenness and happiness. For the participants, the association between alcoholic beverages, happiness, fun, and parties encourages drinking; normal and pathological drinking take place as a continuum; happiness is subordinated to alcohol use. The study offers bases for community health care.

Descriptors: Alcoholism; Anthropology, Cultural; Family; Public Health.

\footnotetext{
*Trabalho premiado com Menção Honrosa no X Encontro de Pesquisadores em Saúde Mental e de Especialistas em Enfermagem Psiquiátrica. Ribeirão Preto, SP, Brasil, 2008. Resulta de pesquisa desenvolvida dentro do Programa de Capacitação em Investigação sobre o Fenômeno das Drogas - PREINVEST -, promovido pela Organização dos Estados Americanos (OEA) e Escola de Enfermagem de Ribeirão Preto, da Universidade de São Paulo.

${ }^{\dagger}$ This study received an Honorable Mention at the $10^{\text {th }}$ Meeting of Researchers in Mental Health and Psychiatric Nursing. Ribeirão Preto, SP, Brazil, 2008. This study was developed as part of the Program for Training in Investigation about the Drug Phenomena (Programa de Capacitação em Investigação sobre o Fenômeno das Drogas - PREINVEST), promoted by the American States Organization (Organização dos Estados Americanos -OEA) and the Escola de Enfermagem de Ribeirão Preto da Universidade de São Paulo.

1-Antropóloga, Doutor em Antropologia Social, Professor Doutor, Escola de Enfermagem de Ribeirão Preto, Universidade de São Paulo, Centro Colaborador da OMS para o Desenvolvimento da Pesquisa em Enfermagem, SP, Brasil. E-mail: mccosta@eerp.usp.br

2-Enfermeiro, Mestre em Enfermagem, Professor, Escuela de Enfermería Dr. Gladys Román de Cisneros, Facultad de Ciencias de la Salud, Universidad de Carabobo, Venezuela.
}

Autor Correspondente: Maria Cristina Silva Costa. Endereço para Correspondência: Universidade de São Paulo, Escola de Enfermagem de Ribeirão Preto, Departamento de Enfermagem Psiquiátrica e Ciência Humanas, Avenida Bandeirantes, 3900, Bairro Monte Alegre, CEP: 14040-902, Ribeirão Preto, SP, Brasil. E-mail: mccosta@eerp.usp.br 


\section{CONSUMO DE ALCOHOL EN UNA COMUNIDAD VENEZOLANA: INVESTIGACIÓN ETNOGRÁFICA ${ }^{\ddagger}$}

Ésta es una investigación etnográfica basada en la antropología interpretativa, que apunta a identificar e interpretar significados del consumo de alcohol en una comunidad venezolana. Participaron miembros adultos de seis familias de la comunidad. Observación participativa y entrevistas fueron las técnicas utilizadas. Los sentidos identificados en el análisis de datos convergen en tres unidades de significación: consumo excesivo, embriaguez y alegría. Para los participantes, la asociación de bebidas alcohólicas, alegría, diversión y fiesta motiva para beber, la ingesta alcohólica normal y patológica se disponen en continuidad; la felicidad se subordina al consumo de alcohol. La investigación ofrece bases para la atención a la salud de la comunidad.

Descriptores: Alcoholismo; Antropología Cultural; Familia; Salud Pública.

\footnotetext{
${ }^{\ddagger}$ Trabajo premiado con Mención de Honor en el X Encuentro de Investigadores en Salud Mental y de Especialistas en Enfermería Psiquiátrica. Ribeirao Preto, SP, Brasil, 2008. Resulta de la investigación desarrollada dentro del Programa de Capacitación en Investigación sobre el Fenómeno de las Drogas PREINVEST-, promovido por la Organización de Estados Americanos (OEA) y la Escola de Enfermagem de Ribeirao Preto de la Universidade de São Paulo.
} 


\section{Introdução}

A maioria dos países, nas últimas décadas, tem enfrentado graves problemas devidos ao uso de drogas, entre elas, o álcool. A população consumidora de álcool cresceu em escala mundial e o início deste consumo ocorre em idade cada vez menor. Na segunda metade do século XX, nos Estados Unidos, aproximadamente 9 milhões de adultos enfrentavam problemas com o uso abusivo de álcool ${ }^{(1-2)}$. Na Venezuela, os consumidores habituais de bebidas alcoólicas somavam 5.722.000, na década de 90, numa proporção de 30 em cada 1000 habitantes, com um consumo médio anual de 13 litros por pessoa maior de 15 $\operatorname{anos}^{(1,3)}$.

O alcoolismo passou a ser considerado doença, e por isso tornou-se objeto de estudo da medicina, em meados do século XIX ${ }^{(4)}$. En 1955, a Organização Mundial da Saúde reconheceu a relação entre alcoolismo e "perturbações mentais": "Son alcohólicos los que beben en exceso y cuya dependencia respecto del alcohol ha alcanzado un grado tal que determina la aparición de visibles perturbaciones mentales, o cierta interferencia en la salud física y mental, en las relaciones interpersonales, y en el adecuado funcionamiento social y económico"(5) $^{(5)}$ O alcoolismo foi reconhecido pela Assembléia Mundial da Saúde, em 1976, em sua definição da "síndrome de dependência do álcool", como "estado psíquico e habitualmente também físico" caracterizado por uma compulsão para beber álcool de maneira contínua ou periódica com o objetivo de experimentar efeitos psíquicos, podendo apresentar, ou não, tolerância ${ }^{(6)}$. Definido como doença física e psíquica, o 
alcoolismo tornou-se, também, objeto de investigações sociais, desde a década de sessenta do século $\mathrm{XX}^{(7)}$.

Pesquisas epidemiológicas realizadas nos últimos 20 anos revelam que o álcool é a droga mais consumida pelos jovens, que a ele chegam numa espécie de rito de iniciação à adolescência, tendo assimilado a concepção de que as bebidas alcoólicas são ingredientes indispensáveis de qualquer festa. A vinculação entre diversão e álcool não é um fenômeno localizado; aparece associada a 5\% das mortes de jovens de 15 a 19 anos, em todo o mundo ${ }^{(8)}$.

Pesquisas revelam, ainda, que o consumo de bebidas alcoólicas provoca 4\% de todas as doenças no mundo, sendo, além disso, fator relacionado com 20 a 40\% dos cânceres de esôfago, hepatite, epilepsia, acidentes de trânsito, agressões e homicídios ${ }^{(7)}$. Sem dúvida, configura-se como um problema de saúde coletiva, constituindo um agravante das condições de vida de comunidades pobres ${ }^{(9)}$.

Na Venezuela, o alcoolismo é um grave problema de saúde pública, especialmente nas comunidades das periferias urbanas, nas quais vigem condições de extrema pobreza e exclusão de direitos da maioria da população. O Instituto Nacional de Estatística anuncia que, em 2006, a "pobreza extrema" atingiu $\quad 13,3 \%$ da população venezuelana*, sendo consideradas nesta condição aquelas famílias cujo consumo é inferior a uma cesta básica (valor entre 500000 e 650000/Bolívar Venezuelano $)^{(9)}$. Em média, as famílias venezuelanas das periferias urbanas têm renda mensal inferior ao montante necessário para a cesta básica. Elas

\footnotetext{
* Em 2005, 37,9\% da população venezuelana encontrava-se abaixo da linha da pobreza.
} 
constituem o grupo mais vulnerável para as drogas na Venezuela, com início do consumo em idade precoce (10 a 19 anos) e, sobretudo, de bebidas alcoólicas ${ }^{(10)}$.

Nessa população, cresce o uso de psicofármacos e outras drogas, sendo o álcool a droga mais consumida. A relação entre consumo de álcool e traumatismos ou lesões por causa externa, reconhecida por instituições internacionais (nas Américas, 43,9\% dos traumatismos e 28,1\% das lesões ocorrem entre pessoas que fizeram uso recente de álcool ${ }^{(10)}$ ), se revela mais grave em comunidades pobres. Na comunidade focalizada neste trabalho, a cada dez delitos cometidos, sete o são sob efeito de drogas, ou com o objetivo de conseguir dinheiro para comprá-las $^{(11)}$.

Não obstante exista significativa informação sobre o tema, poucos estudos abordam valores e motivações associados ao consumo de bebidas alcoólicas, que envolvam o contexto sociocultural e focalizem a dimensão cultural do problema. Ademais, estudos realizados em comunidades marginalizadas, com este enfoque, não foram encontrados. Tal omissão justifica abordar o consumo de bebidas alcoólicas como expressão de uma realidade simbólica, que diz respeito a sujeitos concretos e a problemas enfrentados por famílias de comunidades marcadas por grande privação. Isto levou à proposição desta pesquisa, que teve o objetivo de interpretar os significados do consumo de álcool em famílias de uma comunidade de periferia urbana.

\section{Metodologia}

A pesquisa foi desenvolvida em 2007, na Venezuela, obedeceu às 
exigências éticas de pesquisas com seres humanos e recebeu aprovação da Comisión de Ética de la Escuela de Enfermería de la Universidad de Carabobo.

Para a inclusão dos sujeitos, consideraram-se os seguintes critérios: membros de famílias (pais, mães e filhos) que residem na comunidade Brisas de Carabobo, adultos de 20 a 60 anos, de ambos os sexos, consumidores ou não de álcool, com acesso aos estabelecimentos de saúde que prestam assistência à comunidade e que aceitassem participar do estudo. Entre dez famílias selecionadas aleatoriamente, seis atendiam a todos os critérios, compondo um grupo de vinte sujeitos (6 pais, 6 mães e 8 filhos).

A etnografia, compreendida como uma "descrição densa" ${ }^{(12)}$ - uma descrição que busca significados -, foi o método de estudo escolhido. Orientada teoricamente pela antropologia interpretativa, que integra o paradigma hermenêutico ${ }^{(13-14)}$, a pesquisa buscou interpretar significados de práticas, motivações, concepções, integrando-os em seu contexto cultural.

Para desvendar a lógica cultural que orienta os significados das condutas e valores relativos às bebidas alcoólicas, na comunidade, as principais técnicas de pesquisa utilizadas foram: observação participante e entrevistas em profundidade. As entrevistas, gravadas e transcritas literalmente, desenvolveram-se como diálogos entre pesquisador e pesquisados $^{(14)}$. A $\quad$ observação concretizou-se com a participação do investigador em distintas situações de vida dos sujeitos: seu cotidiano familiar, festas, atividades de lazer, reunião de amigos. A utilização da técnica de observação participante permitiu 
apreender ações efetivas e superar os limites da entrevista, pelo confronto entre o que dizem os sujeitos e o que fazem.

A análise dos dados exigiu repetidas leituras das transcrições de entrevistas e anotações de observações, identificação de semelhanças e diferenças entre ações e concepções, organização dos dados em unidades de significados, elaboração de núcleos de significação e contextualização cultural, nos termos da interpretação hermenêutica ${ }^{(14)}$.

\section{Resultados}

A vida na comunidade Brisas de Carabobo

Localizada na periferia do município de Naguanagua, na área geográfica de Valencia, capital do Estado de Carabobo, a comunidade Brisas de Carabobo, fundada em 1983, possui uma população de aproximadamente 5.400 habitantes, segundo informações do conselho comunitário. Os adultos trabalham predominantemente no comércio informal ou prestam serviços em caráter eventual a instituições; alguns homens trabalham como pedreiros, vendedores ou cobradores (muitos sem contrato de trabalho); numerosas mulheres recebem ajudas governamentais através de programas assistenciais.

A maioria das habitações situa-se em blocos residenciais, possui luz elétrica e recebe abastecimento de água intermitente (suspenso alguns dias da semana). No interior da comunidade localizam-se um ambulatório e um consultório popular, que prestam assistência de saúde aos moradores. Ali estão, também, dois pontos licenciados de 
comércio de bebidas, cujos proprietários relatam vender por volta de 50 caixas semanais de bebidas alcoólicas. Além disso, é possível constatar que muitos lares se convertem em bodegas clandestinas.

Todos os dias, especialmente depois das 17 horas, pode-se observar, na comunidade, a presença de adultos $\mathrm{e}$ jovens, nos locais de venda de bebidas. Após o término da jornada de trabalho, muitas pessoas passam horas consumindo bebidas alcoólicas nos bares (principalmente cerveja) e, por vezes, até amanhecem em meio à cantoria ou música tocada em alto volume. Nos finais de semana, ou quando existe um motivo especial para celebração, os encontros em bares se ampliam.

\section{Observação e entrevistas} revelaram que, na comunidade, as reuniões festivas das famílias e os encontros entre amigos são vividos como ocasião de compartilhar uns tragos. Em festas familiares é possível presenciar membros das famílias oferecerem cerveja ou vinho a crianças, celebrando com risos, aplausos e frases, como a que diz um pai a seu pequeno filho: ${ }_{i}$ Esto es para que vallan aprendiendo desde niño y cuando sea grande no lo engañen!(pai)

O consumo de álcool entre famílias da comunidade

Pela análise dos dados, constataram-se coincidências e divergências entre os sujeitos da pesquisa, quanto às condutas frente ao álcool e aos sentidos a ele atribuídos.

Em todas as famílias investigadas, existe o consumo de bebidas alcoólicas, por um ou mais membros, sendo esporádico em duas delas e, em quatro, 
habitual, principalmente nos fins de semana; porém, em uma destas observase o consumo diário. Portanto, o uso de bebidas alcoólicas, ocasional ou frequente, pelo menos por um dos membros da família, constitui uma característica comum a todas.

As principais particularidades observadas, quanto ao consumo de bebidas, foram: maior aceitação entre os jovens; maior rejeição entre as mães. As convergências de sentidos revelaram-se, contudo, mais significativas que as diferenças. Estas convergências permitiram identificar três unidades de significados: consumo excessivo, embriaguez e alegria.

Consumo excessivo

O uso habitual de bebidas alcoólicas observado na comunidade e relatado pelos entrevistados é definido, por muitos, como "consumo excessivo" e constatado, particularmente, entre jovens. As famílias não hesitam em destacar o grande consumo dessas bebidas pelos jovens como um grave problema enfrentado pela comunidade. De acordo com os depoimentos, este consumo excessivo pelos jovens ocorre nos finais de semana e festas: se ve en los jóvenes demasiado excesivo porque a veces están más pendientes de la rumbita, que también con la rumba viene la bebida. Por ejemplo los jóvenes esperan los fines de semana, la rumba, la cosa el alcohol por supuesto, le puede hacer daño, quizás al principio no pero con el paso del tiempo si va haciendo habito, piden fiado a la comida pero dejan el salario para tener más para consumir la cerveza[...] (mãe).

A maioria dos jovens participantes relata consumo habitual de bebidas alcoólicas e três deles admitem o uso de outras drogas. Muitos deles reconhecem 
seu consumo como excessivo e alguns até relatam empenho em modificar sua conduta ante as bebidas: Desde mi punto de vista es un relajante de la gente, bueno cuando bebo, me hace sentir bien, me siento alegre, a veces cuando venía del trabajo estresado me bebía un trago, ahora estoy alejado del alcohol porque sé que no es algo bueno. Yo llegué a ser tan adicto al alcohol que dejaba de comprar mis cosas para irme a rumbear y a beber [...] (filho). Segundo os relatos, não há diferenças nos comportamentos de gênero, quando se trata de beber: te diré que tomamos a la par, bueno si conozco hombres que toman así muy pausado mientras se toma una, a mi me a tocado consumiendo unas cuantas cervecitas, mientras él se ha tomado una yo me he tomado tres, no es equitativo, pues, la mujer puede consumir menos por supuesto que no, a veces las mujeres jalan mas que los hombres, pues al menos al grupo que yo conozco la mujeres le llevan una morena a los hombres (pai). Entretanto, observa-se o consumo maior e mais frequente entre homens adultos e entre jovens de ambos os sexos, do que entre as mães participantes deste estudo. Embora admitam que o consumo de bebidas alcoólicas no ambiente familiar ocorre principalmente em festas, oito sujeitos narram o uso cotidiano de bebidas em seus lares: Bueno a nivel de las fiestas no te puedo hablar mucho, porque así fiesta no, bebo aquí mismo en la casa, mi marido me compra la cerveza, como para que no ande en la calle buscando (mãe). Um pai afirma beber, em casa ou em bar, todos los 365 días del año.

\section{Embriaguez}

Nas entrevistas, todos os sujeitos reconhecem os efeitos prejudiciais do álcool sobre o organismo, ressaltando o mal-estar advindo da embriaguez: bueno, el ratón que queda que no es nada agradable, pésimo, pega temblores, dolor de cabeza pero uno tantea no le pasa eso y vuelve otra vez, y que se 
toma otra para quitarse el ratón (pai). A maioria enfatiza a embriaguez e suas consequências (náuseas, vômitos, tontura, dor de cabeça e, ainda, certos comportamentos) como os principais malefícios trazidos pelo consumo excessivo de bebidas.

Doenças crônicas também constituem consequências destacadas, predominantemente pelos adultos, ao reconhecerem os prejuízos orgânicos causados pelo álcool. Uma mãe narra enfermidade hepática do cunhado, devida ao constante uso abusivo de bebida alcoólica. Um pai, que relata seu empenho em deixar de consumir álcool, diz: Ayer no bebí tampoco, ya no me hace falta. Pero si tengo muchos amigos [...] uno murió de cirrosis hepática. Tengo amigo que ha quedado lisiado, amputado de una pierna. Um jovem descreve os efeitos maléficos da bebida em seu organismo, ressaltando tanto o mal-estar da embriaguez, quanto danos permanentes nos órgãos: produce deseos de vomitar, me hace mareado, caminar de lado, acostado todo me da vuelta, ardor estomacal, mucha sed, deseo de ir a orinar cada momento, produce daño en el hígado (filho).

Os efeitos sobre a mente e as modificações de condutas sob a influência do álcool são também ressaltados: uno se alegra pero a la hora de la verdad da miedo, mucha persona tiene una personalidad sin beber alcohol, cuando toman tienen otra personalidad agresiva (pai). Uma mãe lembra de problemas familiares enfrentados em sua infância e adolescência, quando o pai, embriagado, tornava-se agressivo ou caía na rua. Outra mãe descreve o que observa em si mesma e nos outros: Hay unos que se ponen pichacoso, otros que le pegan la jodedera, se ponen mas alegres, se sueltan un poco mas, verdad que es horrible beber con gente que le gusta buscar problema, o sea lo que llaman mala bebidas, pues, apenas se toman 5 o 6 y ya se creen súper hombres buscándoles camorras. 
Bueno, a mi me provoca bailar mas nada, y la comida se olvida si me la ponen me la como, si no, no. Alguns relatos explicitam a compulsão para continuar a beber: Bueno lo que primero que siento cosquilleo por el cerebro, es seguir, o sea, aumenta el apetito por el aguardiente, por eso es que uno no debe decir me voy a beber unas tres mas es mentira después de la tercera vienen las demás y de allí pierden la cuenta (mãe).

Entre as condutas predominantemente associadas ao consumo de bebidas alcoólicas mais destacadas pelos jovens, estão: hace que cometa errores, te acueste con hombres (filha), sentirse agresivo, fogosidad y calor (filho), con ganas de bailar (filha). Alguns relacionam beber e acidentes de trânsito, mas, em geral, os jovens enfatizam as relações entre o consumo de álcool e a violação de padrões de conduta: cuando uno toma por supuesto se siente más alegre, más desinhibida, eres capaz de hacer cosas que normalmente sin tener una de gota de alcohol encima no haría (filha). Lo que le pasó una amiga es que terminó teniendo relaciones sexuales el que conoció esa noche, sin mayores, termina en camas ajenas (filha).

Pais e mães atribuem grande importância aos problemas desencadeados nos relacionamentos familiares pelos efeitos do álcool, sobretudo, brigas do casal, quando ambos bebem, agressões e, até mesmo, as reações envergonhadas do círculo familiar diante do comportamento de pais ou mães alcoolizados. Uma mãe revela que, cada vez que o marido se embriaga, instala-se a discórdia entre eles. Outra relata: entre mi hermana y mi cuñado, hubo un enfrentamiento pues, yo estoy segura quien animó a presentarse la situación eran que habían tomado cerveza, si hubieran estado sobrio no se enfrenta como lo hicieron.

Os filhos, por sua vez, frequentemente narram problemas que tiveram nas relações com os pais, devidos 
a hábitos relativos às bebidas. Alguns filhos relacionam os hábitos paternos com o próprio comportamento diante da bebida: Anteriormente mientras estaba más pequeña y me podían controlar no me dejaban salir a tomar, pero ahora que estoy más grande y estoy más clara, yo se hasta donde me puedo controlar y yo tengo que cuidar, pero a ello no le agrada mucho eso. Yo creo que en determinado momento mi papá fue un borracho, pero creo que ya superó esa etapa, toma en vez en cuando, pero anteriormente tenía una época que tomaba casi todos los días (filha).

De maneira geral, filhos de pais que abusam habitualmente da bebida demonstram sua preocupação com a saúde deles, como ilustra o depoimento de uma jovem: bueno, es una rotunda y eterna lucha con mi mamá que toma mucho, bueno el efecto que ocasiona en el organismo en el hígado, produce daño, mi mamá toma mucha cerveza y tenemos desacuerdos por esos, y se pone así usted sabes, impertinente, insoportable [...] (filha).

Relatos de episódios de violência e de acidentes relacionados à embriaguez são uma constante nos depoimentos de pais, mães e filhos. Una amiga de mi hija, una compañerita de estudio de ella, está en coma seis años en vida vegetativa que todo tienen que hacérselo, ella no se ha recuperado y saben que esta viva porque respira, fue un accidente con un carro donde lo manejaba una persona borracha (mãe). Outra mãe, que manifesta seu repúdio ao consumo de bebidas e outras drogas, conta o que observa na vizinhança: Aquí al lado viven en bochinche, esta gente todito beben y todo se echan piña, comienza a la 6 y a las 12 de la noche van para el hospital, se echan navajazo y machete, golpean a las personas se vuelven como loco. Los vecinos tenían un gato, le echaron gasolina al pobre gato y le pegaban candela. Eso es sadismo, eso es producto de la droga y del aguardiente, porque ellos venden aguardiente y se forman esos rollos y amanecen en el hospital todo cortado o preso. Um pai narra: He visto pelea fuerte, donde han salido heridos bastante grave; una vez estando en un edificio con un grupo, se resultó una discusión y una persona tomada efectuó unos disparos 
SMAD, Rev. Eletrônica Saúde Mental Álcool Drog. (Ed. port.) 2010 Ago; 6(Especial):514-35

hiriendo a uno que no tenía que ver con la discusión.

Ainda que para vários sujeitos o consumo seja apenas eventual, e alguns se posicionem contrários a ele, todos descrevem casos de amigos ou familiares que fizeram ou fazem uso abusivo de bebidas alcoólicas. A maioria dos sujeitos se manifesta criticamente em relação à embriaguez, referindo-se sempre a condutas de outros.

\section{Alegria}

\section{A principal e mais frequente} motivação para ingerir bebidas, que ressalta das condutas e discursos de pais, mães e filhos, está relacionada com alegria, diversão e festa. Pode-se apreender esta associação no relato de uma mãe: Cuando esta presente el alcohol es diferente que cuando la familia no está tomando, porque cuando hay presencia de alcohol los integrantes se muestran más alegres. Segundo um pai que bebe habitualmente: lo hago por diversión, no lo hago por vicio, consumo casi siempre en los días festivos, en reunión familiar, antes si tomaba más, ya no tomo casi. Yo tomo más cerveza, ahorita estoy tomando una cervecita, pero normalmente estoy tomando vino, estoy en un entorno que me están enseñando como cuidarme un poco más mi salud, dicen que el vino tiene propiedades cardiovasculares. (pai)

Os jovens destacam, entre as suas motivações para beber, a busca de "sentirse bem", "relaxar-se", "alegrar-se" e "relacionar-se": Me hace sentir bien y alegre (filho). Uma filha confirma: consumir alcohol es fiesta, alegría, rumba, celebrar y divertirse. Outra jovem, que credita às bebidas o poder de facilitar interações sociais e estabelecimento de amizades, afirma que elas "ajudam" a liberarse del estrés, ayuda a uno ponerse alegre, librarse de traumas que traen desde pequeño. Outra garota pondera: te lleva a un estado de alegría, que tu te siente bien que te relajan a hacer diferentes 
SMAD, Rev. Eletrônica Saúde Mental Álcool Drog. (Ed. port.) 2010 Ago; 6(Especial):514-35

cosas, como también te puede llevar a un estado de peligro. Um jovem afirma beber porque: casi todo el mundo gusta tomar, sentirse bien, relajarse.

Em segundo lugar, entre as motivações indicadas por todos os subgrupos de sujeitos, aparece o convívio com amigos ou familiares, como esclarece um pai: Mis amigos me decían vamos a jugar, vamos al patio de bola, empezaba, no vale yo me voy para la casa, anda un ratico y después ya nos vamos, el ratico era hasta la doce o una de la madrugada. Outro pai descreve: Consumir es reunirse con un poco de amigos en determinado sitio y beber cerveza hasta que el cuerpo aguante, la cantidad de cerveza que uno pueda consumir.

Muito frequentemente, os sujeitos definem a motivação para beber como mera manifestação de "vontade", como se fosse uma espécie de apetite por algo, chegando a bebida a ser concebida como um bem de consumo familiar qualquer, embora pesem restrições sobre sua venda e seus preços sejam considerados "abusivos". Os depoimentos seguintes ilustram estes aspectos: como ahora hay que madrugar con la ley seca estamos jugando, a parte cuando salió la ley seca todos abusan de los precios (pai). He sabido de gente que cuando cobra la semana de trabajo aparta los gastos de la casa, luz, agua, alimento, pero también aparta lo que le corresponde a la cerveza (mãe). En relación a la venta creo que está un poquito restringida y habido bastante restricciones en eso, claro yo tengo un vecino que vende, alguna veces cuando uno necesita (mãe).

\section{Discussão}

Significados do consumo de bebidas alcoólicas

Nas perspectivas dos pais, mães e filhos, o consumo de bebidas alcoólicas, que é concebido como normal e 
necessário, embora não prioritário, é considerado excessivo entre os jovens, indicando problema social. Os sujeitos sublinham, também, os significados vinculados a comprometimento da integridade física, vício, doença. Contraditoriamente, os jovens concebem as bebidas como relaxantes e todos os subgrupos associam-nas à diversão.

Além disso, os subgrupos coincidem a respeito das ocasiões consideradas propícias ao consumo de bebidas alcoólicas: fins de semana ou dias festivos, encontro de amigos. No entanto, alguns pais e filhos admitem beber todos os dias e a maioria dos jovens relaciona o consumo nos finais de semana com sua ida à discoteca.

Quanto às consequências do consumo de álcool, os subgrupos expressam os problemas de saúde e sociais que constatam: hepáticos, mal- estar geral, cefaléia, náuseas e vômitos, ardor estomacal, acidentes, violência familiar; brigas, ações repudiadas moralmente e dificuldades nos relacionamentos familiares. De maneira contraditória, todos os subgrupos enfatizam que as bebidas deixam as pessoas alegres.

A aprovação do consumo de bebidas alcoólicas pelos sujeitos é relativa a ocasiões especiais, associada a alegria e entretenimento (embora se observe que o uso não está restrito a isto, para muitos). Pais, mães e filhos destacam esta associação, nos significados positivos atribuídos às bebidas, momentos preferenciais de consumo e motivações para beber. Entre os jovens, que expressam maior aceitação, percebe-se, ainda, a exaltação das bebidas como relaxantes e propiciadoras de interação social. Contraditoriamente, todos relatam 
distúrbios na interação social causados pelo consumo excessivo.

Avaliações positivas respaldam suas motivações para o consumo de álcool: estimula a reunião de grupos e famílias, serve para liberar stress, alegrarse, interagir, celebrar datas especiais. Diferentemente, avaliações negativas recobrem suas apreciações a respeito de condutas vinculadas ao álcool: pessoas bebendo nas ruas e bares, violência, acidentes, problemas econômicos, problemas familiares, filhos que compram cervejas para seus pais, escândalos e comportamentos fora das regras sociais. Entretanto, observam-se contradições entre as ações e os julgamentos emitidos nos discursos.

O consumo de qualquer bebida é representado pelos sujeitos como "normal" desde que não ultrapasse os limites de poucos copos. Verifica-se a aceitação do consumo habitual de bebidas alcoólicas pela maioria; no entanto, o consumo considerado excessivo, que resulta em embriaguez e origina condutas desregradas e agressivas, é avaliado negativamente por todos.

No contexto cultural investigado, os significados apontam para o núcleo representado por um contínuo entre o beber "normal", associado à saúde e o beber "anormal", patológico. A quantidade de bebida ingerida marca a distinção entre o "beber diversão" e o "beber doença" (a doença, neste caso, compreendida como em fato biológico, porém também um fato cultural cujos sintomas são as condutas desregradas). Portanto, o consumo de bebidas alcoólicas, que integra a dieta das famílias, só é compreendido como problema, quando em excesso. Diversos estudos expressam a 
importância da vida familiar, na manutenção ou aquisição de hábitos, inclusive das adições ${ }^{(2,4)}$. As condutas das famílias estudadas, ante as bebidas, exercem papel importante na socialização de seus membros e favorecem o desenvolvimento de comportamentos de $\operatorname{adição}^{(2)}$, uma vez que o alcoolismo é considerado a última fase de um processo que inicia com o consumo ocasional, passa pelo consumo moderado e pode derivar em excessivo ${ }^{(3)}$. Talvez o consumo excessivo identificado entre os jovens, pela própria comunidade, revele a influência familiar.

Outro núcleo importante que estrutura a atribuição de significados ao consumo de bebidas alcoólicas se tece na sua associação com alegria, lazer, comemorações, reunião de amigos, o que, evidentemente, não é exclusivo da comunidade estudada e remonta a hábitos arraigados em muitas sociedades. Estes significados relacionam-se com uma concepção de "felicidade consumidora"(15) dependente do consumo hedonista, em que a busca da fruição e do prazer por meio das bebidas (e outras mercadorias) permite superar o stress, as angústias, inseguranças e fraquezas cotidianas.

Nesse aspecto, os sujeitos explicitam uma concepção de felicidade identificada na cultura de massas contemporânea e caracterizada como uma "mitologia euforizante, que caminha lado a lado com o uso cada vez mais maciço de euforizantes (álcool e pílulas tranqüilizantes)"(15). O incremento do uso de bebidas alcoólicas em todo o mundo indica esta tendência; $\quad$ o consumo crescente de bebidas alcoólicas na comunidade, reconhecido como excessivo entre os jovens, revela o agravamento do 
problema social $^{(16)}$.

As tentativas de reduzir o consumo de bebidas alcoólicas, na Venezuela, envolvem intervenções governamentais, com leis que aumentam a taxação de bebidas nacionais e importadas (entre 2006 e 2007 o crescimento foi de 30\%, com novos aumentos garantidos, em outubro de 2007, pela "Ley de impuesto sobre alcohol y especies alcohólicas"(17)). Apesar de as sobretaxas resultarem em aumento dos preços das bebidas pelos comerciantes ou na redução de sua margem de lucro, no caso dos importados, não se verifica diminuição significativa do consumo. As restrições legais à venda de bebidas são burladas pela criação de pontos comerciais clandestinos.

Fato é que a venda e o consumo de bebidas continuam, como se observa na comunidade pesquisada e se escuta dos sujeitos: o objetivo de redução do consumo não foi alcançado ali, com as medidas gerais mencionadas. Certamente, uma intervenção eficaz deveria orientarse pelas lógicas subjacentes às condutas dos atores sociais diante das bebidas e as equipes de saúde podem ser parceiros importantes nessa intervenção.

Como as famílias pesquisadas consomem bebidas alcoólicas em quantidade variável, a equipe responsável pela assistência em saúde deve não só oferecer-lhes assistência relativa a seus problemas físicos, emocionais e de condutas, como também contribuir para que elas cumpram adequadamente sua função socializadora. Para esta assistência, que envolve ações preventivas e de promoção de saúde, a equipe precisa estabelecer vínculos com as famílias, estimulando-as a desenvolver 
competências ${ }^{(18)}$.

\section{Considerações Finais}

A pesquisa revela que os grupos

familiares ingerem habitualmente bebidas

alcoólicas, que esse consumo é maior entre os jovens e que os sujeitos constroem muitos significados semelhantes para essas bebidas, momentos adequados para o consumo, motivações e condutas efetivas associadas ao álcool.

Depreendem-se, por outro lado, importantes contradições, que podem ser reunidas nos significados positivos e negativos atribuídos ao consumo de bebidas alcoólicas: alegria, sociabilidade e festa se contrapõem ao consumo excessivo, à embriaguez, ao vício, à doença. Todos conhecem as consequências prejudiciais do consumo de álcool, mas ele se mantém.

Ante o consumo habitual de álcool pelas famílias pesquisadas, ressalta a responsabilidade da equipe de profissionais de saúde que assistem a comunidade, não apenas de garantir assistência relativa a seus problemas físicos e emocionais, como também contribuir para que elas se invistam de competência para lidar com a questão do consumo de drogas, na socialização de seus jovens membros. O planejamento de ações de saúde relativas ao consumo de bebidas alcoólicas, de importância inquestionável, exige o envolvimento das comunidades para as quais se voltam. Para que se garanta a eficácia das ações, é imprescindível que elas sejam planejadas tomando em consideração os significados expressados pela comunidade. 
A eficácia da assistência em saúde na comunidade estudada exige abordar (e desfazer) a vinculação simbólica entre consumo de álcool, diversão, alegria e felicidade. As ações da equipe poderiam apoiar-se no contínuo identificado entre o "beber normal" e o "beber patológico", ressaltando o outro contínuo observado nos comportamentos sob efeito do álcool, que vão desde as manifestações de alegria até as condutas desregradas repudiadas por todos.

\section{Referências}

1. Castillo CO, Costa MCS. Meanings regarding the use of alcohol in families of a Venezuelan poor community. Rev. Latino-Am. Enfermagem. julho-ago 2008;16 (especial):535-42.

2. Berenson DMD. Family therapy. Alcohol and the family System. New York: Gardener Press; 1976.

3. López CM. Riesgos y beneficios del consumo de bebidas con alcohol: un enfoque de salud pública. Cuad FISAC. (Fundación de Investigaciones Sociales)
2000;1(1):56-78.

4. Velasco FR. Las Adicciones: Manual para Maestros y Padres. México: Trillas; 1997.

5. Barr AD. A Social History of America. New York: Carroll and Graf Publishers; 1999.

6. Pittman DJ. Alcoholismo. Un enfoque interdisciplinario. Buenos Aires: Hormé; 1977.

7. Medina-Mora ME. Patrones de consumo de alcohol en México. En: Alcohol Consumption among Mexicans and Mexican-Americans: a binational 
perspective. California - University of California at Los Angeles (UCLA): Jean Gilbert; 1988.

8. Organización Mundial de la Salud; División de Salud Mental y Prevención del Abuso de Sustancias). Ginebra (SWT); 1993. (WHO/PSA/93.7)

9. Fundación Centro Gumilla (VE). La pobreza a debate. Rev SIC. Marzo 2006;69(682):52-5.

10. Organización Panamericana de la Salud. Las condiciones de salud para las Américas. Washington, D.C.: OPAS; 1998.

11. El fenómeno de las drogas. Caracas, Venezuela: Universidad Católica Andrés Bello (UCAB), Cátedra Libre Antidrogas (Cliad); 2007.

12. Geertz C. A Interpretação das Culturas. Rio de Janeiro: Zahar; 1978.

13. Geertz C. O Saber Local. Novos
Ensaios de Antropologia Interpretativa. Petrópolis: Vozes; 1999.

14. Costa MCS. Intersubjetividade e historicidade: contribuições da moderna hermenêutica à pesquisa etnográfica. Rev. Latino-Am. Enfermagem. maio-jun 2002;10(3):372-82.

15. Morin E. Cultura de Massas no Século XX: neurose. Rio de Janeiro: Forense Universitária; 1997.

16. Gonzales C, Funes J, Gonzales S, Mayol I, Romani O. Repensar Las Drogas. Las Drogas Como Problema Social. Barcelona: Igia; 1988.

17. Decreto Oficial 5.618, de 3 de Octubre 2007 (VE). Gaceta Oficial de Venezuela, $\mathrm{N}^{\circ}$ 5.852; 5 Octubre 2007.

18. Waitzkin N. The Politics of Medical Encounters. How Patients and Doctors Deal With Social Problems. New Haven: Yale University Press; 1991. 


\section{Como citar este artigo:}

Costa MCS, Castillo MCS. Consumo de álcool em uma comunidade venezuelana: Pesquisa etnográfica. SMAD, Rev. Eletrônica Saúde Mental Álcool Drog. (Ed. port.) [Internet]. 2010 [acesso: dia mês abreviado com ponto ano]; 6(Especial):514-35. Disponível em: Endereço Eletrônico Visitado. 